\title{
Análise qualitativa de episódios de interação: uma reflexão sobre procedimentos e formas de uso ${ }^{1}$
}

\author{
Maria Isabel Pedrosa \\ Universidade Federal de Pernambuco ${ }^{2}$ \\ Ana Maria Almeida Carvalho \\ Universidade de São Paulo ${ }^{34}$
}

\begin{abstract}
Resumo
O texto apresenta nossa experiência sobre análise qualitativa de episódios interacionais de crianças em grupo. Focalizam-se diversos aspectos e etapas da análise qualitativa de episódios videogravados. Comenta-se, inicialmente, o recorte do fluxo de eventos gravados para selecionar material para análise, $\mathrm{o}$ recorte interno dos trechos ou episódios selecionados, a transcrição e análise de episódios. A seguir, explora-se, refletindo sobre a evolução do trabalho e exemplificando com casos concretos, diversas formas de trabalhar qualitativamente com episódios, dependendo das perguntas focalizadas e dos objetivos da análise: visando o desenvolvimento de conceitos; visando a análise dos elementos componentes de um processo em foco; ou ainda, para ilustrar, empiricamente, um argumento. Essa diferenciação resultou em outra: a reflexão sobre o nível de detalhamento da descrição adequado a diferentes objetivos de análise e de comunicação. Finalmente, apresentamos nossa experiência em termos de maneiras de ilustrar visualmente dados qualitativos em apresentações escritas ou orais.

Palavras-chave:Metodologia qualitativa; interação criança-criança; análise de episódios de interação.
\end{abstract}

\section{Qualitative Analysis of Interaction Episodes: Some Reflections on Procedures and Usages}

\begin{abstract}
This paper presents our experiences with qualitative analysis of interactional episodes in groups of children. Several aspects and steps of qualitative analyses of videorecorded episodes are focused: The framing of interactional flows to select the fragments to be analyzed, the division of an episode into its component parts and the transcription and analysis of episodes. We explore several ways of working with episodes with a qualitative approach, depending on the questions focused and on the aims of the analysis: a conceptual development; the analysis of component elements of a focused process; or aiming to illustrate an argument with empirical data. This differentiation led to another one: a reflection on the level of descriptive detail adequate to different aims of analysis and communication. We finally present our experiences regarding different forms of visual displays of qualitative data for written or oral presentations.

Keywords: Qualitative methodology; child-child interaction; analysis of interactional episodes.
\end{abstract}

Por mais estruturada e regrada que seja uma área de pesquisa, a análise de dados envolve sempre, em algum grau, o desenvolvimento de recursos e procedimentos novos. Isso é particularmente verdadeiro quando o fenômeno focalizado não tem uma tradição extensa de pesquisa, como é o caso da interação criança-criança em meados da segunda metade do século XX. Essa área, relegada por diversos motivos na pesquisa sobre desenvolvimento até a década de 1970, ressurgiu buscando novas formas de olhar e de explorar o observado (Camaioni, 1980; Carvalho \& Beraldo, 1989). Uma das características dos trabalhos desenvolvidos nesse momento de ressurgimento foi exatamente a busca de procedimentos de análise, que se renovavam praticamente a cada trabalho, como apontou Carvalho (1987, manuscrito não-publicado) em uma comunicação à SBPC: apesar da quantidade e qualidade do trabalho já realizado sobre interação social até essa ocasião, ainda não se dispunha de paradigmas de análise;

\footnotetext{
${ }^{1}$ A elaboração deste artigo foi inspirada por comentários de M. Clotilde RossettiFerreira sobre a utilização da tese de Doutorado Interação criança-criança: um lugar de construção do sujeito como material de discussão em seus cursos. Registramos nosso agradecimento pela utilização de nosso material e por esta inspiração.

2 Pesquisador bolsista do CNPQ.

${ }^{3}$ Pesquisador bolsista do CNPQ. Apoio FAPESP.

${ }^{4}$ Endereço para correspondência: Universidade Federal de Pernambuco, Centro de Filosofia e Ciências Humanasm Departamento de Psicologia, $9^{\circ}$ andar do Centro de Filosofia e Ciências Humanas, Cidade Universitária, 50670 901, Recife, PE. Fone: (81) 21268270; Fax: (81) 21268270.E-mail: icpedrosa@uol.com.br
}

tratava-se de uma área em que, tipicamente, cada pesquisador retomava o trabalho de análise praticamente a partir do zero, quer por insatisfação com as propostas existentes, quer porque estas não se ajustavam a seus objetivos, ou por outras razões. Em cada trabalho sobre interação social com base em dados observacionais reencontrava-se a fase de elaboração de categorias, às vezes com base em sistemas elaborados por outros autores, mas quase sempre envolvendo a proposição de recortes próprios ao trabalho em questão e originados da exploração inicial e familiarização com os dados.

Se isso já ocorria - e possivelmente ainda ocorre - em relação a análises quantitativas baseadas em sistemas de categorias, ainda menos estruturada é a situação de análises qualitativas, baseadas em fluxos interacionais complexos, que requerem modos inovadores - mas nunca arbitrários ou não-justificados - de recorte e de interpretação. Vale a pena ressaltar aqui que, à primeira vista, a análise qualitativa pode parecer, especialmente ao pesquisador inexperiente, mais "fácil", menos exigente em termos de rigor ou precisão, mais fluida ou livre do que a análise quantitativa. Pensamos, ao contrário, que ela exige um esforço muito maior de explicitação de critérios para que o rigor científico seja preservado e para que se torne possível o compartilhamento produtivo de seus procedimentos e de seus resultados.

Em 1985, quando se iniciou o trabalho sobre o qual se baseia este texto, praticamente inexistiam análises qualitativas sobre interação 
criança-criança (1); a própria opção por uma análise qualitativa nesse trabalho não foi feita a priori, mas decorreu do processo de familiarização com os dados a partir das perguntas e do referencial teórico propostos. É a construção desse processo de análise que este artigo visa recuperar e submeter a uma reflexão, na suposição de que compartilhá-la com outros pesquisadores possa contribuir para o avanço da pesquisa na área.

\section{Os Dados sobre os Quais Trabalhamos}

Tínhamos como objetivo estudar a interação social de crianças de um a três anos de idade, concebendo-a como um espaço de inter-regulações no qual se constituem processos psicológicos; dito de outra forma, "investigar as interações sociais como um processo constitutivo da vida mental da criança" (Pedrosa, 1989, p. 63). Propôs-se um trabalho exploratório de análise das várias formas de regulação ligadas ao processo interacional (Carvalho, 1988; Carvalho, Branco, Pedrosa \& Gil, 2002), visando contribuir para melhor compreensão desse processo e de suas implicações na ontogênese da criança. Não se partiu de hipóteses específicas sobre as regulações inerentes às interações de crianças pequenas, nem de categorias previamente elaboradas para a análise dos dados.

Fazia-se necessário, portanto, observar repetidamente a mesma seqüência de ocorrências para que se pudessem alçar as regulações recíprocas inerentes ao processo interacional, a fim de ser possível a análise pretendida, a partir do referencial teórico exposto nesta introdução (Pedrosa, 1989, p. 64).

Esse referencial pode ser resumido, para fins do presente texto, sob duas vertentes: a perspectiva psicoetológica, que sugere ser a interação social um fenômeno ecologicamente relevante, dada a natureza biologicamente social do ser humano; coerentemente com essa perspectiva, buscaram-se subsídios para análise em teorias construtivistas sociointeracionistas (2).

Os dados foram colhidos no decorrer de um ano letivo, em uma creche municipal na região oeste de São Paulo. Foi focalizado o "mini-grupo", composto por crianças de 16 a 30 meses, durante períodos de recreação livre no pátio ou nas salas da creche. Cada sessão, com duração de aproximadamente quarenta minutos, incluía: a) tomadas de varredura, em que eram registradas todas as crianças presentes naquele dia, sua localização e a da educadora, as atividades que desempenhavam, os brinquedos disponíveis etc; b) tomadas focais, em que uma criança era acompanhada durante um tempo pré-definido (mínimo de três minutos, podendo ser ampliado caso a criança se engajasse em um grupo); e, principalmente, c) registros de grupo, em que duas ou mais crianças estavam envolvidas em uma seqüência interacional.

Obteve-se dessa forma, ao longo do ano, uma grande quantidade de material gravado (cerca de 30 horas), o que tornou necessária uma seleção de trechos para transcrição e análise.

\section{O Recorte de Episódios}

Pensamos que o primeiro marco na construção deste procedimento de análise foi a forma de recortar o fluxo interacional videogravado.
Wallon (1941/ 1986) afirma:

Não há observação sem escolha (...). A escolha é determinada pelas relações que podem existir entre o objeto ou o fato e nossas expectativas, em outros termos, nosso desejo, nossa hipótese ou mesmo nossos simples hábitos mentais. As razões da escolha podem ser conscientes ou intencionais, mas podem também nos escapar, porque se confundem, antes de mais nada, com nosso poder de formulação mental (p. 74).

A postura metodológica decorrente é de que o dado é construído, não existe independentemente do observador: é este quem o elege ao status de dado, como fruto de sua reflexão, de sua sensibilidade e, em última análise, de sua interação com os fatos observados. Será que isso implica que o dado é subjetivo e não-compartilhável? Se assim fosse, o próprio empreendimento da construção do conhecimento seria impossível, já que é, necessariamente, um empreendimento coletivo. É a explicitação de critérios que possibilita o compartilhamento e, conseqüentemente, essa construção.

A primeira etapa de nosso procedimento de recorte do material para análise foi a identificação de "episódios". O que é um "episódio"? Em alguns trabalhos, o episódio é definido pelo seu conteúdo em termos de algum sistema prévio de categorização: por exemplo, "episódios agressivos", "episódios de cuidado", "episódios de faz-de-conta" (cf. Castro \& Carvalho, 1981; Lordelo \& Carvalho, 1999; Morais \& Carvalho, 1994). No presente caso, utilizamos um critério baseado na hipótese de interação como regulação recíproca: um episódio é uma seqüência interativa clara e conspícua, ou trechos do registro em que se pode circunscrever um grupo de crianças a partir do arranjo que formam e/ou da atividade que realizam em conjunto.

A delimitação do episódio, seu início ou seu fim, pode ser clara, identificando-se um fato a partir do qual se articula uma seqüência interativa. Por exemplo, no episódio do Apito, uma criança descobriu um apito entre os brinquedos espalhados e o soprou fortemente, provocando um ruído diferente no ambiente. Esse fato em si mesmo não marca um início: é o que ocorre a partir dele que configura um episódio, de onde a necessidade de rever a seqüência no vídeo para identificar o fato que lhe dá origem.

\section{Episódio do Apito}

O episódio gira em torno de um apito: uma menina $(\mathrm{Lu})$ encontra-o entre os brinquedos espalhados no chão, e apita. Depois o coloca na boca de Vânia, que também dá umas apitadinhas. O som do apito parece chamar a atenção de outras crianças, que se aproximam. Lu coloca o apito, em rodízio, na boca de cada criança que está em torno dela, e também em sua própria boca. Todos apitam várias vezes até que $\mathrm{Lu}$ se vira e se afasta, levando o apito e limpando-o em sua roupa.

Outras vezes, o episódio emerge de uma situação onde vários elementos se combinam - uma palavra, um gesto, um riso, um brinquedo, etc - e se constituem em uma seqüência, uma brincadeira, p. ex.. Mais uma vez, não se reconhece inicialmente que esses elementos pertençam a um episódio ou dêem início a ele. Seguindo-se o registro, identifica-se uma brincadeira com 
uma certa configuração; volta-se, então, a observar o registro, procurando os elementos que foram articulados e desencadearam aquela brincadeira. Neste caso, às vezes não é possível dizer quando o episódio começou, e se toma arbitrariamente um dado momento para iniciar a transcrição e a análise.

\section{Episódio Encontro no Sofá}

Neste episódio, o sofá a um canto da sala é o local de encontro de várias crianças que chegam, saem, retornam ou não, desenvolvendo vários temas de brincadeira. Optou-se por tratar esses vários momentos como uma única seqüência, ao invés de recortá-lo em diversos episódios, com base na centralidade do sofá como marco do local de encontro, e na permanência de uma menina que desde o início está brincando nesse local. O início não é definido por nenhum evento. A descrição do episódio foi iniciada a partir do momento em que a menina está sentada no sofá, brincando sozinha de dar comidinha a uma cabeça de porco. O tema "dar comidinha" persiste ao longo do episódio, desempenhado por várias crianças e intercalado com outros temas relacionados: "pentear" ou "ensaboar" o cabelo da outra criança com um pedaço de madeira, segurar um objeto diante da boca do porco em postura de dar mamadeira, verbalizações "nenê" e outras que indicam uma articulação de temas em torno de familia, relação mãe-filho, casinha.

Da mesma forma que o início, o término do episódio pode acontecer claramente ou exigir uma decisão do pesquisador para determinar o seu fim. Pode-se citar, como exemplo do primeiro caso, o episódio das Carreiras, que foi interrompido pela educadora quando colocou uma caixa de brinquedos no chão. Um exemplo do segundo caso é o episódio Empilhando Cubos, onde a pesquisadora interrompeu a transcrição e análise quando o foco da filmagem foi desviado para uma das crianças do grupo que se afastou com um brinquedo e constituiu uma díade com outra criança.

\section{Episódio das Carreiras}

As crianças correm pela sala em ritmos variados e em roteiros organizados, de acordo com diversas propostas que surgem e se modificam ao longo da brincadeira: correr de um lado para outro da sala e cair ao chegar à parede; correr num roteiro circular; correr em rodopios; correr até o fundo da sala, escorar a mão no quadro de giz, esperar o parceiro, voltar e fazer o mesmo do lado oposto; correr balançando a cabeça; correr em torno de "cachorrinhos" (crianças de gatinhas mimetizando cachorros); correr em torno de uma criança passando a mão em sua cabeça. $\mathrm{O}$ episódio revela o movimento do grupo de crianças que, em diversos momentos, aglutinam-se e se dividem formando composições sociais variadas, subgrupos que se coordenam em atividades complementares e com revezamento de papéis. Cerca de cinco minutos após o início, a educadora coloca no chão uma caixa de brinquedos. Todas as crianças se aproximam e as "carreiras" são interrompidas.

\section{Episódio Empilhando Cubos}

É um episódio complexo, que poderia ser considerado como o entrelaçamento de vários episódios: a constituição de uma díade ( $\mathrm{Lu}$ e Daniel) que se destaca no grupo e interage durante quase todo o episódio empilhando conjuntamente cubos de papelão; diversas ocorrências em torno da posse e apropriação de objetos; uma sucessão de aproximações e afastamentos de uma menina (Eli) em relação ao grupo, talvez tentando incorporar-se a ele. A unidade do episódio é dada pela configuração espacial, pelos objetos com os quais as crianças brincam e pelo fato de que os vários eventos simultâneos vão sendo monitorados pelas crianças e têm um potencial regulador que se evidencia no entrelaçamento das ocorrências.

Uma vez identificado um conjunto de episódios (no conjunto das 41 sessões, foram identificados grosseiramente 160 episódios), foram selecionados alguns deles para análise, com base em dois critérios: a participação de pelo menos duas das seis crianças que permaneceram no grupo durante todo o período de coleta - de forma a garantir um mínimo de continuidade dos dados - e a época de ocorrência do episódio: nos meses iniciais, nos meses finais e nos meses intermediários, para permitir uma análise de eventuais transformações ocorridas no processo interacional ao longo do período focalizado. A seleção resultou em 11 episódios (quatro nos períodos inicial e final, e três no período intermediário) para serem transcritos e analisados em detalhe. Note-se que a seleção de episódios decorre necessariamente dos objetivos particulares de cada estudo; no caso que estamos descrevendo aqui, o tempo e a continuidade dos sujeitos foram considerados os critérios mais relevantes, mas outros critérios poderiam ser utilizados para outros objetivos, como veremos adiante.

\section{O Recorte Interno dos Episódios}

O contínuo do registro recortado em episódios revelou-se ainda grande demais para análise. Decidiu-se, então, realizar um recorte interno ao episódio, que consideramos o segundo marco no processo de desenvolvimento deste procedimento. Os episódios foram divididos em momentos, de modo a permitir, primeiro, esquadrinhar o próprio episódio, alcançando-o em detalhes que se perderiam em uma descrição mais global e, segundo, traçar os arranjos que poderiam refletir a estruturação ou organização do espaço interacional construído pelas crianças.

Os critérios para recortar os episódios em momentos foram bastante flexíveis. Em alguns casos seguiu-se a pista dos arranjos formados pela identidade das crianças que compõem o grupo em diferentes instantes, ou seja, recortava-se um momento quando se alterava a composição social do grupo. Em outros casos, recortavamse os momentos a partir dos arranjos formados pela configuração da brincadeira que estava sendo realizada, seguindo pistas tais como o conteúdo da brincadeira, a distribuição espacial, a movimentação envolvida, etc.

Os critérios para recortar o episódio em momentos, por serem flexíveis, exigiam tomadas de decisão do pesquisador. Era simples quando se seguia a pista da composição social do grupo: a cada modificação, correspondia um novo momento. Mas seguir a outra pista, a da configuração da brincadeira, já implicava algumas decisões, como a abrangência maior ou menor de um momento. $\mathrm{O}$ episódio das Carreiras, já mencionado, serve para ilustrar esse ponto: poderse-ia recortar um só momento no qual as crianças corriam de um lado para outro da sala; mas esse mesmo contínuo poderia ser recortado em vários momentos, delimitados pelas carreiras sucessivas de um lado para outro. 
Uma outra dificuldade pode ser discutida: algumas brincadeiras têm uma configuração explícita para o adulto, com pistas verbais ou sinalizações iguais às que ele usa. Mas às vezes não é isso que acontece, principalmente no caso de crianças menores, que usam pistas rápidas, ambíguas e sutis - um olhar, um riso, um gesto imitativo; o roteiro da brincadeira não é claro para o adulto, que já se desabituou de decodificar intencionalmente esses tipos de sinais e tem dificuldade de perceber do que as crianças estão brincando, ou mesmo se estão brincando juntas, compartilhadamente. Chega-se a dizer que a criança pequena tem uma brincadeira paralela, e não uma brincadeira interativa, tal a dificuldade de perceber a estrutura da interação. Isso dificulta e pode fazer com que pareça arbitrário o recorte em momentos.

Mais uma dificuldade se acrescenta quando se recorta o episódio conjugando-se os dois critérios para a delimitação dos momentos: o arranjo da composição social do grupo e o arranjo da configuração da brincadeira. Por exemplo, no episódio Empilhando Cubos, a chegada e a saída de uma criança que tentava se introduzir nas atividades de outras crianças foram usadas para marcar os limites dos momentos; mas, em certa ocasião, aquela criança saiu, voltou e saiu outra vez, dentro de um mesmo momento; é que, nesse caso, preferiu-se não interromper uma seqüência interativa que estava acontecendo com outras três crianças do grupo.

Diante desses comentários, o leitor pode estar se perguntando: se a pista da composição social do grupo é mais simples, por que não é a única utilizada? Há duas razões. Em primeiro lugar, algumas vezes o episódio transcorre sem que se altere a composição social do grupo e, apesar disso, a configuração da brincadeira se altera, refletindo uma nova maneira de estruturação do grupo. Em segundo lugar, e mais importante, a decisão de recortar o episódio em tais ou quais momentos depende do que se quer evidenciar, do que é relevante para a discussão. Recortar o episódio de um determinado jeito ajuda ou dificulta alçar os dados, e ajuda ou dificulta apresentá-los de modo mais claro. Mais uma vez fica evidente a interação do observador com o observado.

Um exemplo pode ser mais esclarecedor. No episódio Empilhando Cubos, chamou a atenção do pesquisador o fato de uma criança chegar ao grupo depois da brincadeira estar iniciada: o grupo já empilhava cubos ou brincava de carrinhos, e esses brinquedos já estavam divididos entre as crianças presentes. A criança chegou e saiu várias vezes do grupo e, em cada ocasião, fazia uma coisa diferente: pegou um objeto de um menino e o entregou de volta; derrubou os cubos empilhados; chegou falando algo que não se entendia. Esses vários comportamentos sugeriram ao pesquisador o uso de diferentes estratégias para se introduzir no grupo e brincar também. Para analisar essa possibilidade, pareceu interessante recortar o episódio em momentos tomando-se como critério as sucessivas idas da criança até o grupo, ou seja, a composição social do grupo, de forma a ressaltar o fato a ser analisado.

Note-se, ainda, que o desenrolar das transcrições propiciava uma melhor apreensão do espaço interativo das crianças e, com isso, alterava-se a própria previsão de recortes em momentos. Observar também é um fenômeno interativo, no qual o observador é modificado pelo observado. Procedia-se da seguinte forma: o episódio era visto várias vezes, e se anotavam as partes de que se compunha a brincadeira. Esse primeiro passo assemelhava-se à tarefa de contar a alguém de que as crianças brincavam, como brincavam e com quem brincavam. Tentava-se também, provisoriamente, uma representação gráfica para cada momento do episódio. Em seguida iniciava-se a transcrição, momento por momento, e era nessa hora, com os detalhes anotados, e percebendo-se a influência das ações de cada criança sobre a outra ou sobre o grupo, que os momentos se configuravam mais nitidamente. Avaliava-se então, com base na percepção sobre como a estruturação do espaço interacional regulava o comportamento da criança ou sugeria um desdobramento da brincadeira, a conveniência de ajustar ou não o recorte inicial dos episódios a algum novo dado.

\section{A Transcrição e Análise dos Episódios}

Descrevemos aqui o procedimento original de transcrição, a partir do qual, em trabalhos posteriores, foram resumidos ou selecionados trechos em outros momentos e para outras finalidades, como será comentado adiante.

Originalmente foram utilizados dois tipos de transcrição dos episódios. O primeiro privilegiava uma seqüência de interação identificada e somente descrevia o comportamento de outras crianças em cena se estas estivessem diretamente relacionadas à seqüência. $\mathrm{O}$ interesse era seguir a trama interacional, procurando identificar seu encadeamento e desdobramento. No episódio do Apito, já resumido, foi utilizado este tipo de transcrição: as crianças só são mencionadas quando se orientam para a brincadeira do apito.

A outra forma de transcrever os episódios procurava informar sobre todos os comportamentos das crianças em cena. Era utilizado quando se desejava comentar as regulações recíprocas entre as crianças presentes na cena, estando ou não envolvidas em uma seqüência interacional explicitada. Nesta segunda forma pode-se, por exemplo, discutir o espaço interacional de crianças em brincadeira solitária ou paralela, ou a diferenciação de crianças em díades a partir de um grupo maior.

O nível de detalhamentos das transcrições também envolvia decisões que nem sempre eram fáceis. Adotou-se a seguinte regra: somente eram transcritos em detalhes os comportamentos que fossem esclarecedores para a compreensão das regulações no espaço interacional. Com base nessa regra, não eram descritas em minúcias morfológicas, por exemplo, a postura da criança, uma ação de encaixar, de pegar ou de empilhar; mas indicava-se se a criança se debruçou sobre a outra, movimentou-se, acocorou-se, afastou-se, etc, sempre que isso informasse sobre a configuração do grupo, a atração por um brinquedo ou por uma brincadeira, ou por outra criança, ou ainda, e principalmente, quando indicasse que a outra criança fez uma ação semelhante, complementar ou aparentemente desconectada da ação da outra.

O comportamento de "olhar" merece um comentário especial. Nem sempre é possível diferenciar com segurança, a partir do registro, a direção do olhar: para a outra criança, para o brinquedo que está em sua mão, para o seu rosto, etc. Qual a relevância desta limitação? Em primeiro lugar, mesmo que o foco do olhar seja identificado, isso não implica que não estejam sendo percebidas coisas em volta; mas, principalmente, ao discutir as interações de crianças como espaço de inter-regulações, não pretendíamos identificar o estímulo específico que supostamente causa o comportamento do(s) outro(s), até porque 
supõem-se causações múltiplas. Um objetivo diferente poderia requerer uma identificação mais precisa da direção dos olhares - por exemplo, se a pergunta se referisse à orientação da atenção da criança em relação a aspectos do ambiente ou a diferentes parceiros, de forma a traçar um quadro sobre a estrutura de atenção do grupo.

$\mathrm{Na}$ transcrição dos episódios, foram acrescentadas às vezes impressões provocadas no pesquisador pelas ações das crianças, indicando-se esse fato com frases como "é como se ...", "parece que ...", “dá a impressão de que ...". Pesquisadores mais rigorosos provavelmente não admitiriam esse tipo de comentário, considerandoos interpretações subjetivas. Pensamos, no entanto, que esses comentários acrescentam "cor" ou "tom" às situações descritas, e podem propiciar uma compreensão melhor do episódio; como já foi dito antes, admitimos que o registro e leitura dos dados são feitos de modo interativo com o pesquisador.

A análise dos dados iniciou-se a partir da transcrição, de forma gradativa, episódio por episódio. Foi guiada, em cada momento, pela pergunta: o que está regulando as interações dessas crianças? E as respostas eram novas perguntas: será o ritmo de seus movimentos? $\mathrm{O}$ arranjo da brincadeira? O diálogo entre elas? $\mathrm{O}$ recorte de uma ação elevado ao status de uma proposta para o grupo de brinquedo? Uma regra subjacente à brincadeira? Uma previsão ou expectativa da criança?

Após a formulação dessas perguntas/ respostas, voltava-se ao episódio para rever detalhes relevantes; nesse momento, podia ocorrer uma lembrança de um fato análogo já acontecido no grupo, que podia ser retomado revendo-se episódios anteriormente analisados, e sugerir indícios interessantes. Todos esses indícios, perguntas, suposições, respostas provisórias eram anotados, indicando-se as ocorrências às quais se relacionavam. Reviam-se as formulações teóricas subjacentes a cada uma dessas direções, de forma a reafirmar ou não as pistas que conduziam a elas. Tudo isso, evidentemente, orientava a observação de outros episódios ainda a serem transcritos.

Pensamos que esse tipo de análise inicial, exaustiva, minuciosa, principalmente sempre carregada de curiosidade e de indagações, foi fundamental para os desenvolvimentos posteriores de nosso trabalho. No entanto, revendo a história da construção desse trabalho, reconhecemos diferentes formas possíveis de utilização da análise qualitativa de episódios e, conseqüentemente, diferentes formas de transcrição, sobre as quais refletimos a seguir.

\section{Diferentes Formas de Trabalhar Qualitativamente com Episódios}

\section{Análise de Episódios para a Construção de Conceitos Teóricos}

A tese à qual nos referimos aqui (Pedrosa, 1989) consistiu basicamente em um esforço de elaboração de conceitos que contribuíssem para a compreensão do processo interacional como espaço de construção do sujeito. Partindo da noção de que a interação social é um processo de regulações recíprocas, buscamos identificar a natureza dessas regulações. Esse caminho conduziu ao desenvolvimento de conceitos descritivos e teóricos. No primeiro caso podem ser situados os conceitos de recorte, proposta e arranjo, que detalharemos um pouco mais neste texto, e que abriram caminho para um segundo momento: o desenvolvimento da noção de arranjo no conceito teórico de atrator (Pedrosa, Carvalho \& ImpérioHamburger, 1997); a explicitação do conceito de regulação e seu desdobramento nos conceitos de regulação, regulação recíproca e correlação; e, a partir destes, a proposição de princípios ou mecanismos da sociabilidade - orientação da atenção, compartilhamento de significados, persistência de significados, e vínculo como produto e instrumento de compartilhamento e de persistência de significados (Carvalho, Império-Hamburger \& Pedrosa, 1998; Carvalho \& Rubiano, 2004).

A primeira etapa da análise de resultados na tese foi a demonstração de ocorrência de regulações recíprocas entre as crianças. Evidenciamos essa ocorrência apontando aspectos dos episódios descritos que demonstravam ajustamentos de ações compondo uma atividade conjunta; em seguida, procuramos sistematizar as várias formas de regulação que podiam ser depreendidas dos episódios. Não se trata de um sistema de categorias; não há implicação de que os aspectos recortados sejam mutuamente exclusivos ou operem isoladamente no sentido de fatores determinantes, ou ainda de que possam ser dispostos hierarquicamente.

a) O recorte e a proposta

A noção de recorte implica uma seleção, pela criança, de uma ação ou de um aspecto de uma ação de outra ou outras crianças. Essa seleção tem o potencial de desencadear uma atividade compartilhada, e evidencia a regulação da primeira criança pela ação de outra(s). Por exemplo, no episódio "Dêta, dêta", descrito em detalhes em Pedrosa \& Carvalho (1995), Vânia aproxima-se de Viviane, senta-se a seu lado, dá um gritinho; nesse momento, Viviane deita-se; Vânia debruça-se sobre ela, e em seguida sentase; Viviane senta-se e Vânia deita-se. A ação de Viviane de deitarse como que foi recortada por Vânia, constituindo a possibilidade de uma brincadeira de deita-senta alternadamente, que continuou por alguns minutos e posteriormente difundiu-se no grupo, desencadeada pelo recorte do deitar de Viviane por Vânia.

$O$ recorte pode cumprir uma função de sinalização de disponibilidade para iniciar uma seqüência interativa, como ocorreu nesse caso. Chamamos essa ocorrência de proposta, para sugerir o potencial que tem a ação de servir de pista para orientar ou reorientar a atividade. Ela não se restringe, no entanto, a ações seguidas pelo parceiro ou pelo grupo: uma proposta pode ser aceita ou não. As idéias de recorte e proposta não se confundem: ao recortar a ação do parceiro, a criança é regulada por ele - é como se atribuísse a essa ação o status de proposta; ao devolver essa atribuição ao outro ela a torna uma proposta, uma nova forma de regulação potencial de sua ação e da ação do outro. O recorte também pode regular a ação da criança sem que ela o ofereça para ser compartilhado - por exemplo, reorientando uma atividade solitária. Isso ressalta o fato de que a atividade solitária não se opõe à interação social, é um momento desta. Mesmo as propostas não seguidas implicam novos ajustamentos, reorientações e coordenações e constituem, portanto, parte do processo de regulação e do campo interacional.

Também ocorrem no grupo muitas ações que podem ser consideradas propostas, mas que não são recortes de ações do outro: são ações novas no grupo, ou uma variação do que já estava sendo realizado. Nem sempre é possível reconhecer a origem ou o processo de constituição dessas propostas, mas seu 
potencial regulador em geral fica bem evidente. Por exemplo, no episódio "Fingindo dormir", também descrito em Pedrosa \& Carvalho (1995), no $7^{\circ}$ momento Viviane põe-se em pé na cadeirinha do balanço de dois lugares, olha para João Carlos, dá três pulinhos sincronizados com o som "te, te, te" e pára; João Carlos a imita.

b) O "arranjo" da brincadeira

O que chamamos originalmente de "arranjo" é, de certa forma, dificil de definir, mas fácil de reconhecer: um arranjo é o resultado de um conjunto de propriedades de uma situação que faz com que parte dela destaque-se perceptualmente (ou conceitualmente) como uma figura sobre um fundo. É uma configuração que pode ser interpretada ou ter um significado atribuído; que pode transmitir uma informação sobre uma situação que, de outra forma, seria homogênea (só fundo) e, portanto, pouco informativa.

No início do trabalho o "arranjo" foi tratado como uma pista para a descrição feita pelo observador. O exemplo principal, ponto de partida da análise, foi o episódio das Carreiras, já mencionado, que foi diagramado procurando-se ilustrar os sucessivos "arranjos", como na Figura 1. Esse mesmo episódio foi o desencadeador da análise de Pedrosa, Carvalho \& ImpérioHamburger (1997), na qual o conceito de arranjo foi desenvolvido em termos teóricos no conceito de "atrator".

Já se supunha anteriormente, no entanto, que os arranjos tivessem potencial regulador também sobre as crianças. A idéia de regulação pelo arranjo é análoga à de regulação pelo recorte: também aqui a criança efetua um recorte das ações presenciadas, incluindo neste caso a percepção de relações entre os componentes de uma situação e a possibilidade de ser motivada e regulada pela configuração percebida, ajustando-se a ela e/ ou ajustando-a a suas próprias ações. Vários exemplos de episódios selecionados para a análise desta possibilidade são descritos e discutidos em Pedrosa \& Carvalho (1995) e em Carvalho, Império-Hamburger \& Pedrosa (1998). O espaço físico e sua estruturação podem constituir parte componente do arranjo, por exemplo sugerindo um canto de atividades ou um tema de fazde-conta (Campos de Carvalho, Bomfim \& Souza, 2004; Carvalho \& Pedrosa, 2003).

Desta forma, trata-se de um conceito que, ao mesmo tempo, orientou a atenção do pesquisador e sua seleção de episódios e de recortes internos a eles, e propiciou a evolução para o status de conceito teórico útil para a compreensão do processo interacional. Outros exemplos de mecanismos reguladores explorados no trabalho, e que resultaram (ou ainda têm o potencial de resultar) em desenvolvimentos teóricos posteriores foram ajustamentos rítmicos e posturais das crianças, códigos comunicativos, previsões/ expectativas e interpretações, estratégias e imitação.

\section{Análise de Elementos que Compõem um Processo em Foco}

À medida que o pesquisador se expõe repetidamente ao fluxo interacional videogravado, é provável que lhe ocorram determinadas impressões que conduzem a certas perguntas; a análise buscará nos episódios elementos que esclareçam o processo ou processos pertinente(s) a essas perguntas.

Escolhemos dois exemplos de nosso trabalho que nos parecem ilustrar bem essa forma de trabalhar qualitativamente com episódios. Em Pedrosa \& Carvalho (1995), a pergunta refere-se à noção de construção da brincadeira na interação social. A noção, evidentemente, já se baseia em pressupostos teóricos sobre a interação - no caso, a interação criança-criança - como espaço de construção. Foram selecionados e descritos dois episódios lúdicos, utilizando-se a descrição sob a forma de momentos para permitir que o leitor acompanhasse a análise detalhada da construção da brincadeira. Nessa análise, os conceitos de recorte, proposta, ajustamentos rítmicos e posturais, turnos, emergem como conceitos úteis não apenas do ponto de vista descritivo, mas também para a compreensão do processo de construção.
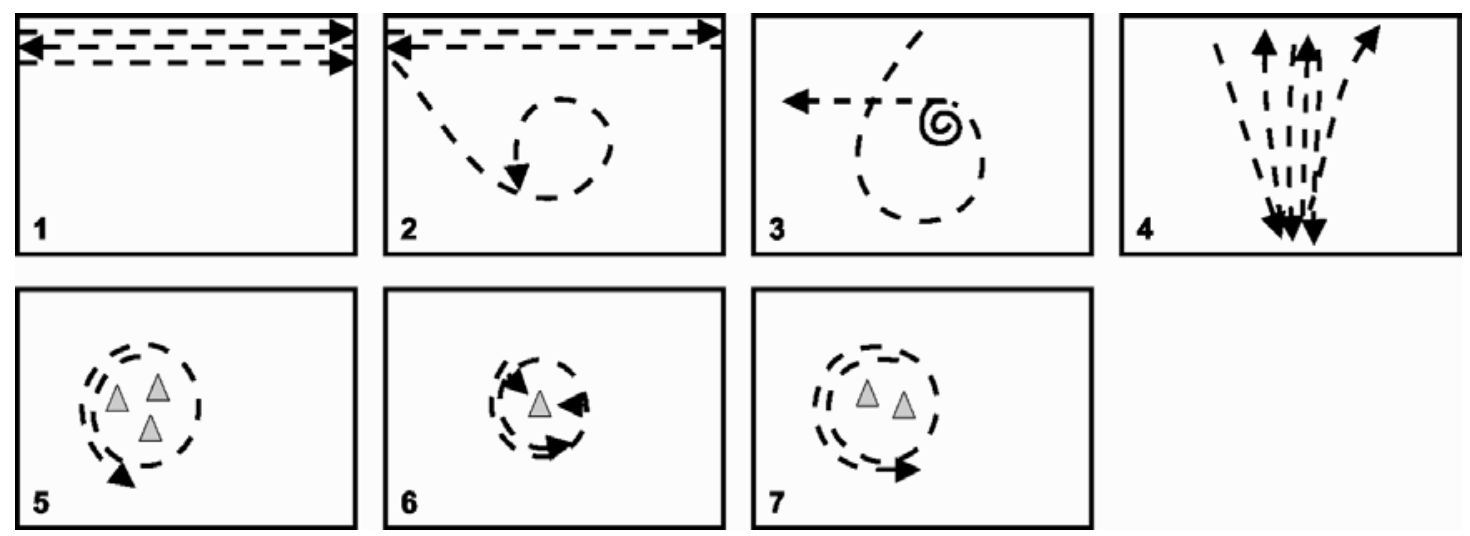

Figura 1. Representação esquemática do episódio das Carreiras.

Legenda:

1. Correndo pela sala e caindo no chão junto à parede

2. Dois grupos em rotas diferentes: através da sala e em rota circular

3. Rodopio de mãos dadas

4. Correndo até o fim da sala e de volta para a parede oposta

5. Correndo em torno de parceiros agachados ("cachorros")

6. Correndo em torno de uma criança sentada e afagando seu cabelo

7. Correndo em torno dos "cachorros"

Adaptado de Pedrosa, Carvalho \& Império-Hamburger, 1997. 
No segundo exemplo (Pedrosa \& Carvalho, 2002), a pergunta é mais específica, referindo-se à construção conjunta de conhecimentos sobre eventos físicos. A situação de observação consistia em tríades reunidas em torno de uma mesa onde estavam disponíveis diversos tipos de materiais favorecedores de manipulação exploratória (palitos, massinha, canudos de papelão, garrafas plásticas, argolas, etc). $\mathrm{O}$ conjunto das sessões foi examinado inicialmente em busca de indícios de construção conjunta. Foi identificado um grande número de episódios, entre os quais foram selecionados alguns que envolviam mais claramente aprendizagens ou construção de conhecimento sobre eventos físicos. A análise desses episódios conduziu à identificação de quatro modalidades de construção, com base na dinâmica do episódio e na literatura pertinente: (1) a criança tenta repetir um resultado obtido casualmente pelo parceiro; (2) a criança imita o resultado obtido pelo parceiro, mas não os meios pelos quais ele o obteve; (3) a criança cria um procedimento mais ao alcance de suas possibilidades para chegar ao resultado obtido pelo parceiro; (4) a criança ajuda o parceiro a obter um resultado através de demonstração de meios para obtê-lo. Essas modalidades são discutidas à luz da literatura sobre imitação e sobre suas implicações no processo de aquisição da linguagem.

\section{Seleção e Análise de Episódios para Ilustrar Empiricamente um Argumento}

Em outros trabalhos (cf. Morais \& Carvalho, 1994; Carvalho \& Pedrosa, 2002), episódios foram selecionados ad hoc para ilustrar um argumento e/ ou uma interpretação teórica. Por exemplo, para discutir a inserção de elementos macroculturais na brincadeira, já evidenciada em trabalhos anteriores, Morais \& Carvalho selecionaram um episódio em que crianças brincam de "Sinhozinho Malta", um conhecido personagem de novela; ao discutirem a assimilação da cultura do grupo de brinquedo, Carvalho e Pedrosa recortaram diversos episódios que ilustravam as modificações na fala de uma criança ao longo de um ano, à medida que ela se ajustava ao modo de falar característico de seus parceiros de brincadeira.

A diferença em relação ao caso anterior é que, nestes, os conceitos orientadores da análise não derivaram de um exame detalhado de um ou mais episódios. Estes funcionam, antes, como exemplos de uma argumentação gerada a partir de considerações mais gerais (possivelmente até sugeridas originalmente pela exposição a esse mesmo material, mas não em conseqüência de uma análise detalhada dele). A descrição e análise dos episódios ou a síntese de uma história composta por episódios distribuídos no tempo visam, neste caso, confrontar e examinar esses conceitos e oferecer evidências que permitam ao leitor avaliar sua pertinência e consistência. A título de exemplo, a exposição inicial das pesquisadoras à seqüência de episódios descrita em Carvalho \& Pedrosa (2002), em que uma criança adquire um novo modo de falar, aparentemente regressivo em termos de desenvolvimento e mais característico de seus parceiros de idade, sugeriu originalmente uma reflexão sobre a noção de ganhos e perdas no processo de desenvolvimento (uma reflexão que poderá vir a ser elaborada eventualmente em outro trabalho, com base no mesmo material); mas essa seqüência foi aproveitada, no texto citado, como ilustração do processo de assimilação da cultura do grupo de brinquedo.

Um exemplo de certa forma intermediário entre (2) e (3) é a análise sobre brincadeiras de casinha (Carvalho \& Pedrosa, 2003): a seleção de episódios a serem analisados guiou-se por um tema bem definido (brincar de casinha); mas foi a análise detalhada dos vários episódios selecionados que diferenciou possíveis significados funcionais da brincadeira, como sugere o título desse capítulo. Nesse sentido, a seleção não visou apenas ilustrar um argumento: foi guiada pelo interesse em um fenômeno pré-recortado do ponto de vista temático (de forma análoga à de exemplos mencionados sobre episódios agressivos, afiliativos etc), de maneira a oferecer material empírico que permitisse explorá-lo.

A utilidade metodológica de distinguir essas modalidades de utilização de análise qualitativa é que o nível de detalhamento descritivo pode variar entre elas. Quando a análise qualitativa visa a exploração de um fenômeno recortado segundo conceitos como interação e regulação, em busca de compreensão de seus processos e mecanismos, é necessário um detalhamento maior para oferecer pistas para essa busca. Em outros casos pode ser útil uma descrição mais focalizada em aspectos já delimitados no objetivo da análise (como no item 2, citado anteriormente) ou uma descrição mais global, a título de ilustração de um argumento (item 3). Cada um desses casos é ilustrado nos vários trabalhos referidos neste tópico, e algumas considerações mais pontuais são abordadas a seguir.

\section{O Nível de Detalhamento da Descrição: Análise e Comunicação}

Como foi apontado no item anterior, o nível de detalhamento da descrição pode ser variável dependendo do objetivo. Para fins de análise, a descrição é geralmente mais minuciosa, enfatizando os indicadores que guiam a análise. Um exemplo é a forma de descrição adotada na tese, em que cada episódio selecionado foi inicialmente descrito de acordo com o roteiro resumido na Figura 2.
Título
Data
Duração
Crianças envolvidas (gênero, idade)
Situação: resumo geral do ambiente físico onde se desenrola o episódio
Resumo: síntese do próprio episódio
Descrição: descrição detalhada de cada um dos momentos em que o episódio foi recortado, indicando-se os minutos e segundos em que eles se iniciam

Figura 2. Roteiro de descrição de um episódio. 
Por outro lado, para fins de comunicação uma descrição detalhada pode ser desnecessária e desaconselhável, por distrair a atenção do leitor e deixar de enfatizar os aspectos que se deseja destacar. Uma comparação entre diferentes formas de descrição de um mesmo episódio pode ser feita entre as descrições do episódio Fingindo Dormir em diferentes contextos de trabalho.

\section{Fingindo Dormir}

(1) Pedrosa \& Carvalho, 1995

Duração: 7' 17"

Idade das crianças: 2;1 a 2;9 (média: 2;5)

Situação e Resumo: as crianças recreiam no pátio, onde existe apenas um brinquedo: um balanço de duas cadeirinhas. $\mathrm{O}$ episódio se inicia quando Lucinéia se aproxima do balanço e acontece uma cena agonística: Lucinéia se introduz no balanço e Viviane, João e Alexandre, que já estão lá, tentam impedí-la; cena parecida se repete, mais adiante, entre Viviane e João, mas esta se transforma em uma seqüência sincronizada de movimentos e sonorizações. Constrói-se, entre as crianças, uma brincadeira de fechar os olhos encostando a cabeça no espaldar da cadeira.

\section{Descrição}

$1^{\circ}$ momento: (1'22") - Lucinéia chega até o balanço, onde estavam outras três crianças: Viviane e João sentados e Alexandre, fora do balanço, impulsionando-o. Lucinéia senta-se na grade inferior do balanço. Alexandre empurra Lucinéia com o pé; João bate nela com a mão, falando "sai". Viviane também a empurra; João e Alexandre puxam os cabelos de Lucinéia, que choraminga, mas continua sentada; pára de choramingar e olha para Viviane.

$2^{\circ}$ momento: (1' 48") - João sai. Alexandre volta a impulsionar o balanço. Alexandre puxa outra vez o cabelo de Lucinéia.

$3^{\circ}$ momento: (2' 36") - Lucinéia se afasta. Alexandre se senta, encosta a cabeça no espaldar da cadeira e fecha os olhos por um instante. Viviane olha para ele (quando ele já está de olhos abertos) e também encosta sua cabeça do mesmo jeito. Alexandre levanta-se; olha atentamente para Viviane. Viviane desencosta a cabeça; Alexandre aproxima-se e empurra, levemente, a cabeça dela, como que para encostá-la outra vez; ele ri, desce do balanço e fala alguma coisa. Ela se desencosta, olhando para ele. Alexandre impulsiona o balanço, inclina ligeiramente a cabeça para trás e fecha os olhos. Viviane olha para ele.

$4^{\circ}$ momento: (3' 41") - Alexandre sobe no balanço e se aproxima de Viviane; tenta encostá-la, mas Viviane se antecipa. Alexandre põe dois dedinhos sobre os olhos dela para fechá-los; ela ri, passa a mão em um dos olhos e encosta a cabeça nessa mão, escorando o braço na cadeira. Alexandre aproxima-se mais e, com um dedo, cuidadosamente, baixa a pálpebra do olho de Viviane. Ela, em seguida, abre o olho. Lucinéia volta ao balanço, senta-se na cadeira oposta e olha para os dois. Alexandre continua fechando o olho de Viviane, que o abre em seguida; faz isso cinco vezes. Vânia aproximase do balanço e fica olhando.

$5^{\circ}$ momento: (4'22") - Lucinéia se levanta, ficando atrás de Alexandre. Este se volta para ela. Lucinéia se senta. Alexandre bate nela.

$6^{\circ}$ momento: (4' 59") - João chega até o balanço e se orienta para Viviane, falando algo; tem-se a impressão de que ele quer um cantinho na cadeira. Viviane o empurra com a mão e se põe em pé na cadeira. João estira a língua para ela com um som "una". Viviane chuta-o de leve. João olha para ela e diz "sai". Viviane repete o "sai" com a mesma entonação e mímica. João faz um ar de riso e repete "sai". Viviane começa a pular e cantar: "pula, pula, pula ... pé, pé, pé”.

$7^{\circ}$ momento: (5' 22") - João entra no balanço e fica em pé, de frente para Viviane. Alexandre e Lucinéia orientam-se para aquela díade. Viviane empurra João com o pé, falando "sail”; este diz: "ai, não, (?)ocou”. Viviane olha João, dá três pulos sincrônicos com o som "té, té, té", e pára. João faz igual enquanto Viviane olha; ele pára; Viviane ensaia pulinhos (apenas faz a flexão do corpo, sem levantar os pés da cadeira), falando "té, té, té, té"; depois continua flexionando o corpo para baixo e para cima de modo mais lento, sonorizando no ritmo da flexão. Sem que Viviane páre, João faz igual a ela, introduzindo-se corretamente na seqüência, ou seja, flexionando o corpo para baixo no momento em que ela também flexiona para baixo. João continua a seqüência com uns pulinhos miúdos e rápidos. Viviane dá mais uns pulinhos cantando "Bahia, Bahia". Ela pára e faz outro movimento de flexão para trás, sempre sonorizando no mesmo ritmo do movimento.

$8^{\circ}$ momento: (5' 52") - Alexandre desce do balanço e começa a impulsioná-lo.

$9^{\circ}$ momento: (6' 14") - Daniela chega perto do balanço, pelo lado oposto ao de Alexandre, e fala: "pala aí, pala aí. Oh nenê, pala â'. Todas as crianças olham para ela. Alexandre pára de impulsionar. Daniela tenta subir no balanço, desiste e ocupa o lugar deixado por Alexandre, impulsionando o balanço. Lucinéia encosta a cabeça no espaldar da cadeira. Alexandre olha para ela e faz igual, fechando os olhos. Lucinéia desencosta a cabeça e olha para Alexandre; encostase outra vez, fechando os olhos. Daniela olha para os dois e ri. Depois, ela própria fecha os olhos, sem parar de balançar. Alexandre e Lucinéia abrem os olhos e riem; Daniela ri também. Os dois encostam a cabeça no espaldar da cadeira e fecham os olhos outra vez. Daniela toca em Alexandre; ele abre os olhos (acorda?) e ri para Daniela. Volta a se encostar e fechar os olhos.

$10^{\circ}$ momento: (7' 53") - Daniela, de repente, dá uns gritinhos fortes e rápidos: "pá, vá, tá". Ela pára de impulsionar o balanço, sobe nele, olha Alexandre e Lucinéia com a cabeça encostada e os olhos fechados; dá umas tapinhas em Lucinéia e fala: "corda, Tiane; corda, Kistiane; corda Kistiane" Lucinéia continua "dormindo", Alexandre também. Daniela aproxima seu rosto do de Lucinéia; Alexandre encosta o rosto no de Daniela. Daniela vê alguma coisa no chão, fora do balanço e diz: “olha! olha, nenê! nenê, olha!”, dirigindose para aquele local. Lucinéia, Alexandre e Vânia também se voltam para lá.

(2) Carvalho, Imperio-Hamburger \& Pedrosa, 1996 Episódio \# 5: Fingindo dormir

As crianças estão brincando no pátio, onde existe apenas um brinquedo: um balanço de duas cadeiras. Uma seqüência agonística ocorre quando Lucinéia (F, 2;9) tenta se introduzir no balanço e é repelida pelas outras crianças que estão lá (Viviane, F, 2;1/ João, M, 2;3/ Alex, M, 2;4). Uma cena semelhante ocorre mais adiante, e já foi descrita no episódio \# 4. Nesse meio tempo, desenvolve-se entre 
Viviane e Alex, e depois entre Alex e Lucinéia, uma brincadeira de "fingir dormir", fechando os olhos e encostando a cabeça no balanço. Uma outra criança (Daniela, F, 2;7) aproxima-se, observa a cena e diz "eu também quelo bincando"; em seguida, sobe no balanço e explicita o significado compartilhado da brincadeira dizendo para Lucinéia: "acorda, acorda". Toda a seqüência é acompanhada por risos e gritinhos por parte das crianças. A duração total do registro é de cerca de 7 minutos.

\section{Episódio \# 4: De um desentendimento a um jogo rítmico}

Viviane (F, 2;1), João (M, 2;3) e Alex (M, 2;4) estão brincando no balanço. Uma outra menina tenta subir no balanço, é repelida com empurrões e puxões de cabelo. João colabora com os outros para repeli-la, mas afasta-se durante esta seqüência, caminhando na direção da pajem e de outras crianças presentes no pátio. Depois de cerca de três minutos, João volta ao balanço, onde Viviane e Alex continuam brincando. João orienta-se para Viviane, que o empurra e põe-se de pé na cadeira do balanço. João mostra a língua para ela, Viviane chutao de leve. João diz "sai" para Viviane. Viviane o imita (mostra a língua e diz "sai" com a mesma intonação). João faz um ar de riso e repete "sai". Viviane começa a pular e a cantarolar: "pula, pula, pula ... pé, pé, pé ...”. João sobe no balanço, orientado para Viviane. Viviane o empurra com o pé, diz “sai”; João responde “ai, não ...”. Viviane dá três pulinhos sincronizados com sonorizações "té, té, té ..." e depois continua a flexionar o corpo de forma mais lenta, emitindo cadenciadamente a mesma sonorização "té, té, té ...". João imita, introduzindo-se no mesmo ritmo de movimentos e sonorizações, ou seja, ajustando-se à proposta de Viviane. Depois de alguns segundos, João pára e olha em outra direção.

O critério principal para a descrição é que ela permita ao leitor acompanhar o argumento, de forma a compartilhar seus fundamentos segundo a análise do autor. Como já foi dito, a análise qualitativa requer uma explicitação ainda mais precisa de critérios do que a análise quantitativa, que é baseada pelo menos parcialmente em critérios já relativamente compartilhados (por exemplo, testes estatísticos; mas não definição de categorias, que sempre deve ser explicitada ou remetida à fonte de onde se originou). A título de exemplo, resumimos a seguir uma análise realizada para apresentação em um simpósio sobre qualidade e quantidade, cuja tônica era exatamente a questão da precisão e do rigor na análise qualitativa (Pedrosa, 2001). O episódio descrito nessa análise (Empilhando Cubos, já resumido neste trabalho) é retomado aqui com o objetivo de ilustrar como o pesquisador pode explicitar os seus critérios e o seu argumento de forma a possibilitar o compartilhamento do conhecimento construído.

\section{Analisando um Episódio}

1. Descrição do episódio observado

Eliane, uma criança de 25 meses, aproxima-se de outras crianças que brincavam predominantemente com cubos (peças de encaixe), sentadas no chão, próximas umas das outras. Eliane, em pé, olha para todas as crianças, parecendo observá-las. Destaca-se uma díade alternando os papéis de empilhar e derrubar os cubos, sinalizando contentamento: gritinhos, agitação do corpo e risadas. Outra criança,
Paola, também de 25 meses, empilha cubos mas não os derruba. Eliane afasta-se e aproxima-se do grupo outra vez. Há uma sucessão de afastamentos e aproximações. Em quatro desses momentos, ela derruba a pilha de Paola, que a recompõe em seguida. Um dos componentes da díade mencionada afasta-se e vai para um cavalinho. Eliane aproxima-se do outro componente, mas este junta os brinquedos, puxando-os para perto de si, e vai na direção do parceiro anterior.

\section{Pergunta}

Por que Eliane derruba sucessivas vezes a pilha de cubos de Paola?

3. Respostas possíveis

$1^{\mathrm{a}}$ resposta, muito freqüente: Eliane quer destruir a brincadeira da outra criança.

$2^{\mathrm{a}}$ resposta, menos freqüente: Eliane quer brincar com as outras crianças.

$\mathrm{N}^{\mathrm{a}}$ outras respostas são possíveis.

4. Pressupostos que orientam as respostas

Qualquer resposta implica suposições sobre a criança - o que ela é capaz de fazer, sua motivação, seu desenvolvimento. Em qualquer investigação, essas suposições são premissas e correspondem a generalizações sobre o fenômeno estudado. Por exemplo, respondendo do segundo modo, suponho que a criança tem uma motivação básica para interagir com um parceiro; que uma atividade prioritária no processo interacional é a brincadeira; que o brinquedo é um mediador da interação social, etc. A teoria não apenas orienta o olhar do pesquisador mas, primordialmente, põe a análise dos dados em perspectiva: amplia-se a possibilidade de estender sua reflexão a outras situações. Decorrem, freqüentemente, uma reformulação da pergunta e/ou uma descrição mais "densa" do contexto estudado, bem como das características do sujeito observado.

\section{Exemplo de pergunta}

Que estratégias são usadas pela criança para interagir com um grupo de crianças já estruturado numa atividade de brincar?

6. Descrição "densa" (pontuando os indicadores que guiam a análise)

Eliane tem a atenção voltada para as crianças e os brinquedos.

Eliane observa a díade alternando os papéis de empilhar e derrubar com sinais de contentamento.

Eliane apanha um carrinho e oferece ao menino que brincava de carrinho.

Paola empilhava mas não derrubava.

Eliane apanha um outro carrinho mas o abandona.

Eliane derruba a pilha de Paola, que não ri, não chora e não pede ajuda ao educador (receptividade ou rejeição).

Eliane persiste em derrubar os cubos.

Eliane parece tentar ocupar o lugar deixado por uma das crianças da díade.

Eliane mostra sinais de contentamento (dá gritinhos ao se aproximar). 
Eliane poderia tomar os cubos de Paola, mas não tenta fazê-lo.

\section{Interpretação}

Eliane usa uma estratégia (comum em crianças de sua idade) de imitação da ação de outras crianças para se introduzir num grupo de brincadeira já estruturado: especificamente, a proposição de uma ação complementar à de Paola, a oferta de um carrinho a um dos parceiros que brincava de carrinhos, o posicionamento no lugar anteriormente ocupado por outra criança em uma díade. Esta interpretação fortalece a premissa inicial e a perspectiva teórica a partir da qual foi formulada, e permite a formulação de outras perguntas, por exemplo: as estratégias para interagir, mediadas por objetos, variam em função de quantidade, tipo ou variedade de objetos? Quais estratégias são mais freqüentes? Etc.

\section{Ilustrando Visualmente a Descrição e Análise de Episódios}

Ainda com referência à questão da comunicação de resultados em apresentações orais ou em textos, um aspecto que merece ser considerado é o tipo de material gráfico de apoio. Diferentemente da análise quantitativa, a qualitativa não produz tabelas ou gráficos convencionais. De certa forma, os recursos gráficos poderiam ser considerados dispensáveis neste tipo de análise, baseada principalmente na qualidade e precisão do texto descritivo. Nossa experiência, no entanto, evidencia que esses recursos podem ser muito úteis como recursos para evidenciar e ressaltar para o ouvinte ou leitor os critérios e os aspectos utilizados no desenvolvimento do argumento.

Uma primeira experiência nesse sentido foi realizada na tese, através da elaboração de um diagrama descritivo da movimentação das crianças no episódio das Carreiras (Figura 1, neste texto). Este é um caso particularmente interessante, porque constituiu um ponto de partida para o próprio procedimento de recorte e descrição de episódios, bem como para a elaboração teórica desencadeada a partir daí: ao diagramar a movimentação das crianças, foi possível visualizar o episódio como um evento de grupo, a dinâmica de suas transformações e as pistas sobre os desencadeadores de cada novo momento recortado. Posteriormente, propusemos uma outra forma de representação desse mesmo episódio, em que a identidade das crianças foi preservada, visando aprofundar a reflexão sobre o campo interacional como um sistema de componentes mutuamente regulados (Império-Hamburger, Carvalho \& Pedrosa, 2003, Figura 3).

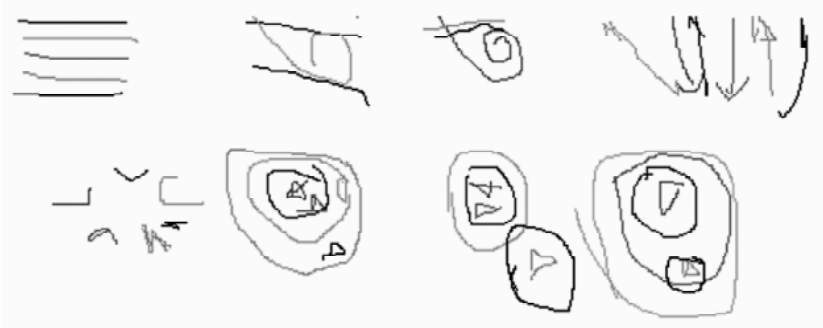

Figura 3. Episódio das Carreiras: representação com identificação das crianças.

Em Império-Hamburger, Carvalho \& Pedrosa, 2003.
Não é qualquer episódio, no entanto, que se presta a esse tipo de representação: apenas aqueles em que os aspectos mais significativos envolvem ações passíveis de serem representadas de forma abstrata, como é o caso de direção de deslocamentos espaciais.

No caso de apresentações orais, é possível utilizar o próprio vídeo como ilustração e base para a argumentação. Esse recurso apresenta, no entanto, alguns inconvenientes, mesmo quando existem boas condições técnicas de apresentação (tela grande, boa qualidade de imagem/ som). Em primeiro lugar, um episódio complexo de interação raramente é apreendido e compreendido em uma primeira exposição; para permitir que o espectador acompanhe a seqüência interacional selecionada, é preciso resumir previamente, ou sinalizar durante a apresentação do vídeo, os aspectos ou momentos relevantes para a análise. Em segundo lugar, a duração dos episódios pode impossibilitar sua apresentação em condições de exposição com tempo muito delimitado.

Uma forma alternativa que utilizamos é fotografar, diretamente do vídeo, os momentos mais representativos ou significativos do
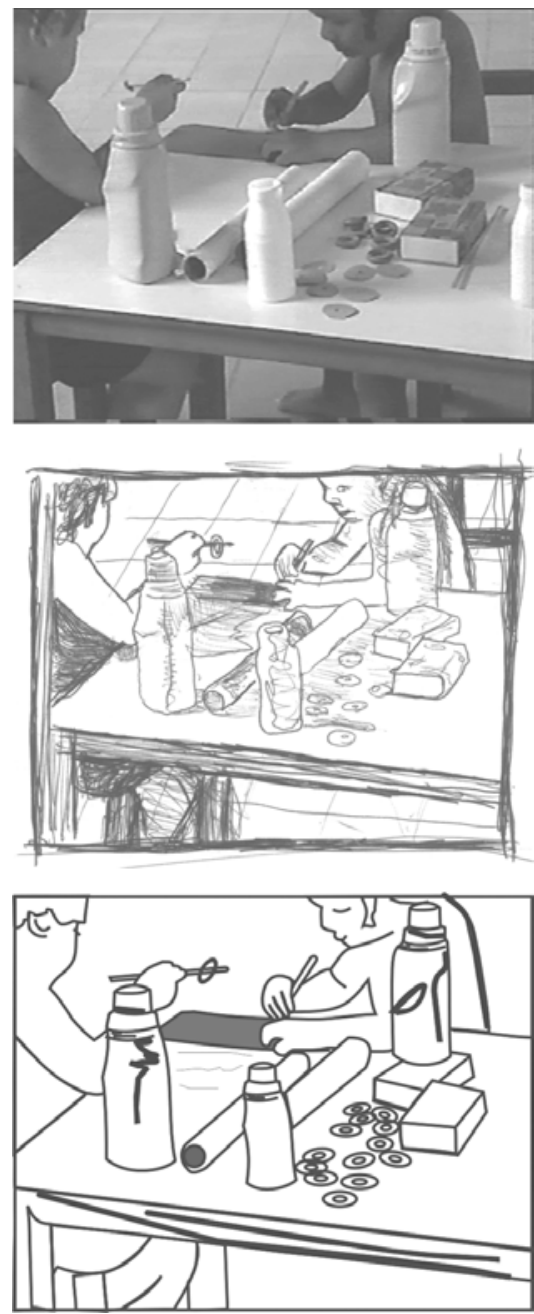

Figura 4. Foto e desenhos da mesma cena do episódio das Argolas.

Desenho de David A.L.Carvalho(2004).E-mail: daviac2003@uol.com.br Produção gráfica deEdite.Com (2004).E-mail: editora@edite.com.br

Psicologia: Reflexão e Crítica, 2005, 18(3), pp.431-442 
episódio para fins de análise e argumentação (3): nesse procedimento, o fluxo de eventos é recortado, sendo as imagens imobilizadas ("desanimadas") de forma a constituir uma seqüência maior ou menor dos momentos mais ilustrativos da descrição e do argumento.

A limitação principal desta modalidade de ilustração visual decorre da própria natureza do registro em vídeo, que freqüentemente se apresenta sobrecarregado de informações, ou com imagens prejudicadas por interferências inevitáveis (uma criança atravessa a tela e encobre parcialmente a ação que se deseja ilustrar, o detalhe de uma ação não é bem visível na foto, etc.). Para certos fins, especialmente quando interessa salientar ações motoras finas, orientação de atenção e outros detalhes, temos experimentado o desenho feito a partir do registro em vídeo e/ou da imagem fotografada (4). Esta opção permite que a informação redundante ou supérflua seja minimizada, salientando-se exatamente os aspectos que se deseja evidenciar em relação à descrição, análise e interpretação. Permite ainda que se desenvolva melhor a "des-animação" do vídeo, recuperando passo a passo as transformações no espaço interacional, como em uma história em quadrinhos, que pode inclusive ser legendada. A Figura 4 contrasta os resultados dessas duas opções de ilustração.

\section{Conclusão}

Ao longo de nossa interação com colegas e alunos que trabalham com abordagens qualitativas a dados de observação, freqüentemente sentimos que fazia falta uma publicação que explicitasse nosso procedimento de trabalho - e sua evolução no decorrer dos anos de forma a propiciar um compartilhamento e uma discussão comparativa dessas abordagens. A tentativa de oferecer uma contribuição nesse sentido foi o objetivo principal deste trabalho, que retoma uma de nossas linhas de produção, a discussão de aspectos metodológicos e de procedimentos (cf. Carvalho \& cols., 1996, 2002; Carvalho \& Morais, 1987; Souza \& Carvalho, 1989). Focalizamos aqui diversos aspectos e etapas da análise qualitativa de episódios videogravados. Em uma primeira etapa, comentamos o recorte do fluxo de eventos gravados de forma a selecionar material para análise, o recorte interno dos trechos ou episódios selecionados, a transcrição e análise de episódios. A seguir exploramos, refletindo sobre a evolução de nosso trabalho no decorrer do tempo e exemplificando com casos concretos de análise, diversas formas de trabalhar qualitativamente com episódios, dependendo das perguntas focalizadas e dos objetivos da análise: visando o desenvolvimento de conceitos (onde explicitamos alguns conceitos descritivos, tais como recorte, momento, proposta e arranjo, e apontamos brevemente conceitos teóricos derivados, tais como atrator); visando a análise dos elementos componentes de um processo em foco; ou ainda com o objetivo de ilustrar empiricamente um argumento. Essa diferenciação conduziu a uma outra: a reflexão sobre o nível de detalhamento da descrição pertinente e adequado a diferentes objetivos de análise e de comunicação. Finalmente, apresentamos nossa experiência em termos de maneiras de ilustrar visualmente a descrição e análise de episódios em apresentações escritas ou orais.
O desenvolvimento deste texto sob a forma de comparações entre estudos que visaram perguntas e níveis de análise diferentes contribuiu para iluminar nossa própria visão e compreensão sobre as questões metodológicas envolvidas na análise qualitativa deste tipo de material. Qualquer análise comparativa - entre culturas, entre grupos sociais, entre espécies animais ou, no caso, mais modestamente, entre diferentes estudos no decorrer de nosso percurso como pesquisadoras - coloca em relevo tanto diferenças quanto semelhanças, o que, a nosso ver, é um alimento muito útil para o exercício da reflexão em qualquer nível. Esperamos que a reflexão que este trabalho desencadeou para nós seja compartilhada e continuada por outros pesquisadores da área.

\section{Referências}

Camaioni, L. (1980). L' interazione tra bambini. Roma: Armando Armando.

Campos de Carvalho, M. I., Bomfim, J. A. \& Souza, T. N. (2004). Organização de ambientes infantis coletivos como contexto de desenvolvimento. Em M. C. Rossetti-Ferreira, K. S. Amorim, A. P. S. Silva \& A. M. A. Carvalho (Orgs.), Redes de significações e o estudo do desenvolvimento bumano (pp. 157-170). Porto Alegre: ArtMed.

Carvalho, A. M. A. (1982). Relações entre pares de idade na infância [Resumos]. Sociedade Brasileira para o Progresso da Ciência (Org.), Ciência e Cultura Resumos (p. 891). Campinas, SP: SBPC.

Carvalho, A. M. A. (1987). Opções metodológicas na descrição da interação social. Comunicação apresentada no simpósio "O trabalho com tecnologia observacional”, na Reunião Anual da Sociedade Brasileira para o Progresso da Ciência, Brasília.

Carvalho, A. M. A. (1988). Algumas reflexões sobre a categoria 'Interação Social' [Trabalho completo]. Em Sociedade de Psicologia de Ribeirão Preto (Org.), Anais da XVIII Reunião Anual da Psicologia (pp. 511-515) Ribeirão Preto, SP: SPRP.

Carvalho, A. M. A. (1989). Brincar junto: natureza e função da interação entre crianças. Em C. Ades (Org.), Etologia: de animais e de homens (pp. 199-210). São Paulo: Edicon/ Edusp.

Carvalho, A. M. A. \& Beraldo, K. E. A. (1989). Interação criança-criança: o ressurgimento de uma área de pesquisa e suas perspectivas. Cadernos de Pesquisa (FCC), 71, 55-61.

Carvalho, A. M. A, Bergamasco, N. H. P., Lyra, M., Pedrosa, M. I., Rubiano, M. R. B., Rossetti-Ferreira, M. C., Oliveira, Z. M. R. \& Vasconcellos, V. M. R. (1996). Registro em vídeo: reflexões a partir de uma troca de experiências. Psicologia: Teoria e Pesquisa, 12, 261-267.

Carvalho, A. M. A., Branco, A. U. A., Pedrosa, M. I. \& Gil, M. S. A. (2002) Dinâmica interacional de crianças em grupo: um ensaio de categorização. Psicologia em Estudo, 7, 91-99.

Carvalho, A. M. A. \& Morais, M. L. S. (1987). A descrição do comportamento social da criança: uma contribuição. Psicologia, 13, 37-54.

Carvalho, A., Imperio-Hamburger, A. \& Pedrosa, M. I. (1996). Interação, regulação e correlação no contexto do desenvolvimento humano: discussão conceitual e exemplos empíricos. SP: Publicações, IFUSP/P-1196, 1-34 (versão preliminar, em português, de Carvalho, Imperio-Hamburger \& Pedrosa, 1998).

Carvalho, A., Império-Hamburger, A. \& Pedrosa, M. I. (1998). Interaction, regulation and correlation in the context of human development: Conceptual discussion and empirical examples. Em M. Lyra \& J. Valsiner (Eds.), Construction of psychological processes in interpersonal communication (pp. 155-180). Stamford, CT: Ablex.

Carvalho, A. M. A. \& Pedrosa, M. I. (2002). Cultura no grupo de brinquedo. Estudos de Psicologia (Natal), 7 (1), 181-188.

Carvalho, A. M. A. \& Pedrosa, M. I. (2003). Teto, ninho, território: brincadeiras de casinha. Em A. M. A.Carvalho, C. M. C. Magalhães, F. R. Pontes \& I. D. Bichara (Orgs.), Brincadeira e cultura: viajando pelo Brasil que brinca, vol. II Brincadeiras de todos os tempos (pp. 31-48). São Paulo: Casa do Psicólogo. 
Carvalho, A. M. A. \& Pedrosa, M. I. (no prelo). Precursores filogenéticos e ontogenéticos da linguagem: reflexões preliminares. Revista de Ciências Humanas, da UFSC.

Carvalho, A. M. A. \& Rubiano, M. R. B. (2004). Vínculo e compartilhamento na brincadeira de crianças. Em M. C. Rossetti-Ferreira, K. S. Amorim, A. P. S. Silva \& A. M. A. Carvalho (Orgs.), Redes de significações e o estudo do desenvolvimento bumano (pp. 171-187). Porto Alegre: Artes Médicas.

Castro, M. F. \& Carvalho, A. M. A. (1981). Incidentes agressivos na pré-escola. Psicologia, 7 (2), 51-83.

Império-Hamburger, A., Carvalho, A. M. A. \& Pedrosa, M. I. (2003). Movimentos ao acaso e princípios de ordenação em grupos de crianças brincando. Em T. Tomé (Org.), Tendências da Física Estatística no Brasil (pp. 105-109). São Paulo: Ed. Livraria da Física.

Lordelo, E. R. \& Carvalho, A. M. A. (1999). Um estudo naturalístico do comportamento e cuidado entre crianças pré-escolares. Biotemas, 12 (1), 7-30.

Morais, M. L. S. \& Carvalho, A. M. A. (1994). Faz-de-conta: temas, papéis e regras na brincadeira de crianças de quatro anos. Boletim de Psicologia, 44 (100/101), 21 30.

Pedrosa, M. I. (1989). Interação criança-criança: um lugar de construção do sujeito. Tese de Doutorado não-publicada, Curso de Pós-Graduação em Psicologia Experimental, Instituto de Psicologia da Universidade de São Paulo, São Paulo, SP.

Pedrosa, M. I. (2001). A análise qualitativa e a busca de generalidade [Resumos]. Resumos do II Encontro Norte-Nordeste de Psicologia, (CD). Salvador, BA.
Pedrosa, M. I. \& Carvalho, A. M. A. (1995). A interação social e a construção da brincadeira. Cadernos de Pesquisa (FCC), 93, 60-65.

Pedrosa, M. I. \& Carvalho, A. M. A. (2002). Aprendendo sobre eventos físicos com parceiros de idade [Resumos]. Em Associação Nacional de Pesquisa e PósGraduação em Psicologia (Org.), Anais, IX Simpósio de Pesquisa e Intercâmbio Cientifico (pp. 173-174). Águas de Lindóia, SP: ANPEPP.

Pedrosa, M. I., Carvalho, A. M. A. \& Império-Hamburger, A. (1997). From disordered to ordered movement: attractor configuration and development. Em A. Fogel, M. Lyra \& J. Valsiner (Eds.), Dynamics and indeterminism in developmental and social processes (pp. 135-151). Mahwah, NJ: LEA.

Souza, V. H. P. \& Carvalho, A. M. A. (1989). A descrição da movimentação corporal da crianças: uma contribuição para a discussão do conceito de hiperatividade. Boletim de Psicologia, 39 (90/91), 13-26.

Wallon, H. (1986). Como estudar a criança? Em M. J. G. Werebe \& J. NadelBruffert (Orgs.), Henri Wallon (pp. 72-82). São Paulo: Ática. (Original publicado em 1941).

Recebido: 11/03/2004

$1^{a}$ revisão: $11 / 06 / 2004$

Aceite final: $29 / 07 / 2004$

Sobre as autoras

Maria Isabel Pedrosa é Professora de Graduação em Psicologia e do Programa de Pós-Graduação em Educação da UFPE. É Doutora em Psicologia (Universidade de São Paulo) e Pós-Doutora (Duke University, EUA). É pesquisadora do CNPq.

Ana Maria Almeida Carvalho é Professora associada do Departamento de Psicologia Experimental do IPUSP. É Psicóloga, Mestre, Doutora e Livre-docente (USP) e Pós-doutora (Universidade de Sheffield, Inglaterra).

\section{Notas}

1 - Um ensaio anterior de análise qualitativa encontra-se em Carvalho (1982); algumas das observações descritas nessa comunicação foram posteriormente incorporadas em outros textos (cf. Carvalho, 1989).

2 - Um detalhamento dessa fundamentação teórica encontra-se em Pedrosa (1989), pp. 1- 64. Os principais autores interacionistas que compuseram nossa síntese foram Wallon, Piaget e Vygotsky.

3 - Fotografar diretamente a tela com recursos convencionais não é fácil e em geral não produz imagens satisfatórias. Já existem, no entanto, diversos recursos, relativamente simples e acessíveis, para digitalizar imagens de vídeo diretamente da fita para um arquivo que pode ser editado (cf, por exemplo, WinTV). Exemplos de imagens produzidas através de fotografia convencional encontram-se em Pedrosa e Carvalho (1995) e Carvalho, ImpérioHamburger e Pedrosa (1998). Imagens digitalizadas diretamente encontram-se em Carvalho e Pedrosa, 2003.

4 - Essa opção depende da disponibilidade de colaboradores que sejam capazes de recriar a imagem em desenho, ou de extrair dela um desenho esquemático, simplificado, seja feito à mão ou através de computação gráfica. Um exemplo da primeira alternativa encontra-se em Carvalho e Pedrosa (2003). 